\title{
A negative feedback loop involving NF-KB/TIR8 regulates IL-1 $\beta$-induced epithelial- myofibroblast transdifferentiation in human tubular cells
}

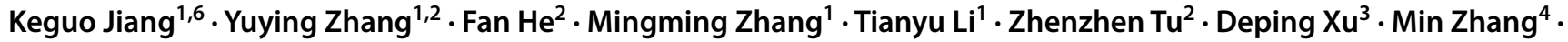 \\ Linzi Han ${ }^{1,2} \cdot$ Liyu Guo ${ }^{2} \cdot$ Haisheng Zhou ${ }^{2,5}$. Deguang Wang ${ }^{1}$
}

Received: 29 March 2021 / Accepted: 18 April 2021 / Published online: 4 May 2021

(c) The Author(s) 2021

\begin{abstract}
Renal tubular epithelial-myofibroblast transdifferentiation (EMT) plays a central role in the development of renal interstitial fibrosis (RIF). The profibrotic cytokine interleukin (IL)-1 and the IL-1 receptor (IL-1R) also participate in RIF development, and Toll/IL-1R 8 (TIR8), a member of the Toll-like receptor superfamily, has been identified as a negative regulator of IL-1R signaling. However, the functions of TIR8 in IL-1-induced RIF remain unknown. Here, human embryonic kidney epithelial cells (HKC) and unilateral ureteric obstruction (UUO)-induced RIF models on SD rats were used to investigate the functions of TIR8 involving IL- $1 \beta$-induced EMT. We showed that IL- $1 \beta$ primarily triggers TIR 8 expression by activating


tion and inhibit IL-1 $\beta$-induced EMT. Moreover, in vitro and in vivo findings revealed that TIR8 downregulation facilitated IL-1 $\beta$-induced NF- $\mathrm{kB}$ activation and contributed to TGF- $\beta 1$-mediated EMT in renal tubular epithelial cells. These results suggested that TIR8 exerts a protective role in IL-1 $\beta$-mediated EMT and potentially represents a new target for RIF treatment.
\end{abstract}

Keywords Epithelial-myofibroblast transdifferentiation $\cdot$ Interleukin- $1 \beta \cdot \mathrm{TIR} 8 \cdot \mathrm{NF}-\mathrm{kB}$

\section{Introduction}

Keguo Jiang and Yuying Zhang have contributed equally to this work.

\section{Haisheng Zhou \\ haishengs@ahmu.edu.cn \\ $\triangle$ Deguang Wang \\ wangdeguang@ahmu.edu.cn}

1 Department of Nephrology, The Second Affiliated Hospital, Anhui Medical University (AHMU), No. 678 Fu Rong Road, Hefei, China

2 Department of Biochemistry and Molecular Biology, AHMU, No. 69 Mei Shan Road, Hefei, China

3 Clinical Laboratory, The Affiliated Hefei Hospital, AHMU, No. 246 Hepin Rd., Hefei, China

4 Clinical Laboratory, The First Affiliated Hospital, AHMU, No. 81 Meishan Rd., Hefei, China

5 Center for Scientific Research, AHMU, No. 69 Mei Shan Road, Hefei, China

6 Department of Nephrology, The Third Affiliated Hospital of Anhui Medical University, No. 390, Huai He Road, Hefei, China
In all forms of progressive kidney disease, the development of renal interstitial fibrosis (RIF) characterized by tubular injury and interstitial fibrosis most reliably predicts the progression toward end-stage renal failure (Meyer 2003); however, little is known about the precise underlying mechanisms. Renal tubular epithelial-myofibroblast transdifferentiation (EMT) is thought to play a central role in RIF development (Acloque et al. 2009; Jinde et al. 2001).

Interleukin (IL)-1 is a proinflammatory, profibrotic cytokine that exerts a wide range of biological effects, including stimulation of proliferation, production of extracellular matrix, induction of leukocyte chemotactic molecule release, augmentation of adhesion molecule expression, and induced release of nitric oxide, reactive oxygen species, and transforming growth factor (TGF)- $\beta$ (Vesey et al. 2002). Additionally, IL-1 is implicated in animal models or human forms of chronic kidney disease, with $I L-1$ expression significantly elevated in experimental glomerulonephritis, whereas blocking IL-1 activity suppresses acute glomerular injury and inhibits RIF (Chen et al. 1997). Moreover, 
IL-1 is capable of inducing morphological and phenotypic transdifferentiation of a normal rat tubular epithelial cell line into myofibroblast-like cells (Vesey et al. 2002). IL-1 $\beta$, as a much stronger inducer of nuclear factor (NF)- $\mathrm{kB}$ response, interacts with IL-1 receptor (IL-1R) to induce EMT by activating the IL-1/IL-1R/NF- $\mathrm{kB}$ signaling pathway (Dinarello and Wolff 1993; Gasse et al. 2007; Zhang et al. 2015). The $\mathrm{NF}-\kappa \mathrm{B}$ complex is usually inactive and located in the cytoplasm while bound to I $\kappa$ B inhibitor proteins; however, after activation of IL-1/IL-1R/NF- $\mathrm{KB}$ signaling, NF- $\mathrm{KB}$ is activated and translocates to the nucleus, where it forms the $\mathrm{p} 65 / \mathrm{p} 50$ complex to control target gene transcription (Gupta et al. 2010; Zheng et al. 2011). Recently, a positive correlation between NF- $\mathrm{KB}$ activation and EMT induction was described in several human cancers (Pires et al. 2017); however, there is no evidence of NF- $\mathrm{\kappa B}$-regulated EMT induction associated with RIF development.

Toll/IL-1R 8 (TIR8), also known as single immunoglobulin IL-1R-associated protein (SIGIRR), is ubiquitously expressed in tissues, particularly in the kidney, digestive tract, liver, lung, and lymphoid organs. In the kidney, it is expressed on the luminal border and basolateral membrane of the proximal tubular cells (Riva et al. 2012). However, the stimuli that induce TIR 8 expression are not yet well defined, and the involved mechanisms are unknown. TIR8 is a member of the IL-1R superfamily (Garlanda et al. 2004) and a fringe member of a family with structural features incompatible with conventional signaling. Additionally, TIR8 has been identified as a negative regulator of the IL-1R signaling pathway (Garlanda et al. 2007; Nam 2006); however, a correlation between activated IL-1R signaling and TIR 8 expression remains poorly defined, especially with respect to a TIR8-related regulatory mechanism involved in IL-1 $\beta$ induced EMT in RIF development.

Therefore, we hypothesized that TIR 8 expression is regulated by NF- $\mathrm{\kappa B}$ and potentially involved in inhibiting NF- $\mathrm{BB}$-dependent EMT induction in human renal tubular epithelial (HKC) cells. We tested this hypothesis by activating IL- $1 \beta / \mathrm{IL}-1 \mathrm{R} / \mathrm{NF}-\mathrm{\kappa B}$ signaling in vitro and demonstrating a negative feedback loop involving NF-кB/TIR8, which regulated in vivo IL-1 $\beta$-induced EMT of tubular cells. The results showed that TIR8, as a negative regulator of the IL-1R signaling, might play a protective role in RIF development and potentially represent a promising new target for RIF treatment.

\section{Materials and methods}

\section{Reagents, plasmids, and antibodies}

Recombinant human IL-1 $\beta$ was purchased from SigmaAldrich (\#SRP3083, St. Louis, MO, USA). The GV248 lentiviral short-hairpin (sh) RNA-expression vector targeting human NF-кB (p65; shp65), human TIR8 (shTIR8), scrambled shRNA (shSc), and the GV248 lentiviral vector were obtained from Genechem (Shanghai, China). The target sequences are listed in Supplementary Table 1. Packaging vectors (pVSVG, $\mathrm{pREV}$, and $\mathrm{pMDL}$ ) were used as described previously (Zha et al. 2015). Human TIR8 cDNA was subcloned at BamHI and EcoRI sites of the pcDNA3.1-C/DYK expression vector.

Primary antibodies used for western blotting analysis include, TIR8 (Abcam, \#ab228977. Cambridge, MA, USA), E-cadherin (CST, \#14,472. Shanghai, China), vimentin (CST, \#5741), p65 (CST, \#8242s), phosphorylated p65 (p-p65 at Ser536. CST, \#3031s), TGF- $\beta 1$ (Proteintech, \#21898-1-AP. Rocky Hill, NJ, USA), glyceraldehyde 3-phosphate dehydrogenase (GAPDH, Image Bioscience, \#IMA1004L. Beijing, China). Primary antibodies against E-cadherin (CST, \#14,472), vimentin (CST, \#5741), p-p65 (Santa Cruz, \#SC136548. CA, USA), TIR8 (Abcam, \#ab228977), IL-1 $\beta$ (Wanleibio, \#WL00891. Shenyang, China), and TGF- $\beta 1$ (Wanleibio, \#WL02193) were used to stain the corresponding proteins, and IgG (CST, \#4414S) was used as a negative control.

\section{Cell lines, cell culture, lentivirus production, and transduction}

HKC epithelial cells were obtained from Peking Union Medical College (Beijing, China). HEK 293T packaging cells have been described previously (Zha et al. 2015). The HKC cells were grown in Dulbecco's modified Eagle medium (DMEM)/F12 supplemented with $10 \%$ fetal bovine serum (FBS). HEK 293T cells were maintained in DMEM supplemented with $10 \%$ FBS and transfected with either of the recombinant vectors or the corresponding control vectors together with packaging plasmids (pVSVG, pREV, and pMDL). Culture supernatants with lentivirus were collected at 48-h post-transfection and used to infect target cells, as described previously (Zha et al. 2015). The recombinant vectors with the human TIR 8 cDNA were transiently transfected into HKC cells using Lipofectamine 3000 (Invitrogen, Carlsbad, CA, USA) according to manufacturer instructions. All of the cells were cultured at $37^{\circ} \mathrm{C}$ in a humidified incubator with $5 \% \mathrm{CO}_{2}$.

\section{Semi-quantitative reverse transcription polymerase chain reaction (qRT-PCR)}

Total RNA isolation, reverse transcription, and semi-quantitative PCR analysis to determine mRNA expression was performed as described previously (Zha et al. 2015). The primer sequences are listed in Supplementary Table 2. 


\section{Western blot and immunofluorescence analyses}

Western blot analysis to determine protein levels was performed as described previously (Zha et al. 2015). Semiquantitative data from densitometric analysis of proteins were obtained using the Gel-Pro analyzer software (https:// omictools.com/gel-pro-analyzer-tool). Indirect immunofluorescence staining was performed using an established procedure on cells cultured in 24-well plates. Briefly, cells were treated accordingly, fixed with $4 \%(\mathrm{w} / \mathrm{v})$ paraformaldehyde for $15 \mathrm{~min}$, blocked with phosphate-buffered saline (PBS) containing 5\% goat serum and $0.1 \%$ Triton X-100 for $20 \mathrm{~min}$ at room temperature, and incubated with specific primary antibodies (CST China). The cells were then routinely stained with fluorescein isothiocyanate-conjugated secondary antibodies (CST China). Cells were also stained with 4',6-diamidino-2-phenylindole for $3 \mathrm{~min}$ to visualize nuclei. Fluorescence was observed and photographed using an Axio Observer 3 inverted fluorescence microscope (Carl Zeiss, Oberkochen, Germany).

\section{Scratch-wound and transwell assays}

Cell motility and migration were evaluated using scratchwound and Transwell assays, respectively. $\mathrm{HKC} / \mathrm{shSc}$ cells and HKC/shTIR8 cells were cultured until near confluency in 6-well plates in the presence of IL-1 $\beta(10 \mathrm{ng} / \mathrm{ml})$, and monolayers were wounded by scratching with a $2-\mu$ l pipet tip. Cells were then incubated in the fresh medium with $2 \%$ FBS and $10 \mathrm{ng} / \mathrm{ml} \mathrm{IL-1} \beta$ for up to $48 \mathrm{~h}$ after wounding. Images of the same area were obtained using a Celldiscoverer 7 (Carl Zeiss, Oberkochen, Germany) at four separate time points $(0,12,24$, and $48 \mathrm{~h})$ along each scratch. Image Pro Plus software (v.6.2; Media Cybernetics, Silver Spring, MD, USA) was used to determine the size of the wound in each image, as well as compare images at each time point with those acquired initially. All experiments were performed in triplicate.

Cells $\left(5 \times 10^{4}\right)$ were seeded onto the filters of tissueculture-treated Transwell plates $\left(8-\mu \mathrm{m}\right.$ pore size, $0.33-\mathrm{cm}^{2}$ growth area; Corning, Corning, NY, USA). After $48 \mathrm{~h}$ of incubation with IL-1 $\beta(10 \mathrm{ng} / \mathrm{ml})$ at $37{ }^{\circ} \mathrm{C}$, filters were fixed with 3\% paraformaldehyde in PBS and stained with $0.1 \%$ Coomassie Blue in 10\% methanol and $10 \%$ acetic acid, and the upper surface of the filter was carefully wiped with a cotton-tipped applicator. Cells that passed through the pores were counted and photographed in five fields. Culture experiments were performed in triplicate.

\section{Experimental models}

SD rats were obtained from the Experimental Animal Center of Anhui Medical University of China. The study were performed in compliance with the Guide for the Care and Use of Laboratory Animals and the ethical guidelines of Anhui Medical University. Experimental UUO was performed on SD rats to establish experimental models of UUO-induced renal fibrosis. Anesthesia was induced with $2 \%$ Nembutal $(3.0 \mathrm{ml} / \mathrm{kg})$, during which the left ureter of each animal was ligated with 4-0 silk at the ureteropelvic junction through a right-flank incision, followed by wound closure in layers. Rates in the sham-operated group had their ureters exposed and manipulated without ligation. After operation, rats were allowed to recover with free access to food and water. Kidneys were harvested at day 21, with 24-h urine and blood samples collected to detect kidney function before termination. The animals were randomly divided into three groups, including control $(n=2)$, sham-operated $(n=4)$, and UUO $(n=11)$ groups.

\section{Immunohistochemistry, hematoxylin \& eosin (H\&E) staining, and masson trichrome staining}

Sections from paraffin-embedded tissues were prepared at $4-\mu \mathrm{m}$ thickness and incubated with anti-IL-1 $\beta$ (1:100), anti-TGF- $\beta 1$ (1:100), anti-TIR8 (1:500), anit-p-p65 (1:50), anti-E-cadherin (1:100), or anti-vimentin (1:200) antibodies overnight at $4{ }^{\circ} \mathrm{C}$, followed by incubation with the appropriate secondary antibody for $1 \mathrm{~h}$ at room temperature. Sections were then stained with H\&E to assess renal injury, and kidney fibrosis was assessed on kidney sections stained with Masson trichrome staining. Blue staining areas represented collagen deposition.

\section{Statistical analysis}

Data were analyzed by one-way analysis of variance using GraphPad Prism software (v.5.0; GraphPad Software, La Jolla, CA, USA). Results are expressed as the mean \pm standard error of the mean, and a $P<0.05$ was considered statistically significant.

\section{Results}

\section{IL-1 $\beta$ regulates TIR8 expression in HKC cells in connection with NF-KB activation}

To investigate whether IL- $1 \beta$ regulates TIR 8 expression in HKC cells, immunoblot analysis was performed to detect TIR8 protein levels and NF- $\mathrm{KB}$ activation in HKC cells treated with IL-1 $\beta(10 \mathrm{ng} / \mathrm{ml})$ for $15 \mathrm{~m}, 30 \mathrm{~m}, 1 \mathrm{~h}, 6 \mathrm{~h}, 12 \mathrm{~h}$, and $24 \mathrm{~h}$. The results showed that TIR 8 expression was significantly and continuously increased in HKC cells by exposure to IL-1 $\beta$, whereas p-p65 levels increased during $15 \mathrm{~m}$ of $\mathrm{IL}-1 \beta$ induction and then decreased gradually after exposure 
to IL-1 $\beta$ for $30 \mathrm{~m}$ to $24 \mathrm{~h}$ (Fig. $1 \mathrm{a}$ and $\mathrm{b}$ ). To determine whether activated NF- $\mathrm{\kappa B}$ directly regulates TIR 8 expression, HKC cells were transfected with shp65 and then exposed to IL-1 $\beta$ for $15 \mathrm{~m}$ and $24 \mathrm{~h}$. Endogenous TIR 8 expression was diminished following p65 knockdown (Fig. 1c).

\section{Ectopic TIR8 expression negatively regulates IL-1 $\beta$-induced NF-KB activation in HKC cells}

TIR8 is a negative regulator of the IL-1R signaling pathway (Garlanda et al. 2007; Nam 2006; Polentarutti et al. 2003); therefore, we hypothesized that TIR 8 overexpression might negatively regulate IL- $1 \beta / \mathrm{IL}-1 \mathrm{R}$ signaling. To test this hypothesis, we established an HKC cell line overexpressing TIR8 (HKC/TIR8). Immunoblot analysis revealed no alterations on p-p65 levels in HKC/TIR8 cells after exposure to IL-1 $\beta$ (Fig. 2a and b). We then established a stable TIR8-knockdown HKC cell line (HKC/shTIR8) to attenuate TIR8 level/activity in HKC cells. Interestingly, western


Fig. 1 IL-1 $\beta$ induces TIR 8 expression in HKC cells in connection with NF- $\kappa \mathrm{B}$ activation. a Western blot analysis of TIR8 levels and $\mathrm{NF}-\kappa \mathrm{B}$ activation (p-p65 levels) in HKC cells treated with $10 \mathrm{ng} / \mathrm{ml}$ IL- $1 \beta$ for $0 \mathrm{~m}, 15 \mathrm{~m}, 30 \mathrm{~m}, 1 \mathrm{~h}, 6 \mathrm{~h}, 12 \mathrm{~h}$, and $24 \mathrm{~h}$. b Semi-quantitative data from densitometric analysis of TIR8 and p-p65 levels are presented as the relative ratio of each protein to GAPDH and p65, respectively. c Western blot analysis of IL- $1 \beta$-induced TIR8 levels and NF- $\kappa \mathrm{B}$ activation in HKC cells transfected with shp65 or shSc blot analysis showed dramatic increases in p-p65 levels in HKC/shTIR8 cells both in the presence and absence of IL-1 $\beta$ within $15 \mathrm{~m}$ (Fig. 2c and d), indicating that ectopic TIR8 expression negatively regulated IL- $1 \beta$-induced NF- $\mathrm{kB}$ activation in $\mathrm{HKC}$ cells.

\section{TIR8 plays a protective role in IL- $\beta$-induced EMT in HKC cells}

A previous study suggested that IL-1 induces transdifferentiation of tubular epithelial cells in renal fibrosis (Torbohm et al. 1989). To evaluate the activation of IL-1 $\beta / \mathrm{IL}-1 \mathrm{R} /$ $\mathrm{NF}-\kappa \mathrm{B}$ signaling in HKC cells, we evaluated IL-1 $\beta$-induced EMT. First, to observe alterations in cell morphology, HKC/ shSc and HKC/shTIR8 cells were cultured in serum-free medium for 3 days with or without IL-1 $\beta$, respectively. As expected, TIR8-knockdown both in the presence and absence of IL-1 $\beta$ displayed significant hypertrophy and lost the cobblestone morphology (Fig. 3a); however, there was less morphological alteration observed in $\mathrm{HKC} / \mathrm{shSc}$ cells in the presence of IL-1 $\beta$.

EMT is associated with loss of the epithelial marker E-cadherin and gain of the mesenchymal markers vimentin, SNAI1 (Snail), Snail homolog protein 2 (Slug), and Twistrelated protein 1 (TWIST1). qRT-PCR to detect mRNA levels of these genes in both $\mathrm{HKC} / \mathrm{shSc}$ and HKC/shTIR8 cells following IL-1 $\beta$ induction revealed decreases in $E$-cadherin expression at 24 and $48 \mathrm{~h}$ (Fig. 3b), whereas IL- $1 \beta$ induced Slug and Twist 1 expression in HKC/shTIR8 cells, although no significant change was noted in the expression of these genes in $\mathrm{HKC} / \mathrm{shSc}$ cells (data not shown). Both immunoblot analysis and immunofluorescence assay showed that IL- $1 \beta$ attenuated E-cadherin levels and upregulated vimentin levels in HKC cells (Fig. 3c and d).

Because TGF- $\beta 1$ is used as a canonical inducer to promote TWIST1 and Slug levels required for EMT, we detected changes in TGF- $\beta 1$ levels in HKC cells by immunoblot analysis. In agreement with a previously report that IL- $1 \beta$ increases expression of TGF- $\beta 1$ (Hao et al. 2011), we observed significant increases in TGF- $\beta 1$ levels in HKC cells treated with IL- $1 \beta$ for 24 and $72 \mathrm{~h}$. Furthermore, we detected higher levels of TGF- $\beta 1$ in HKC/shTIR8 cells in both the presence and absence of IL-1 $\beta$ (Fig. 3e).

EMT is associated with altered cell migration and invasion; therefore, we performed in vitro Transwell migration assays to investigate the invasive capacity of IL- $1 \beta$-induced HKC cells. The results indicated that HKC/shTIR8 cells showed a significant increase in invasive capacity as compared with that of $\mathrm{HKC} / \mathrm{shSc}$ cells following exposure to IL-1 $\beta$ for $48 \mathrm{~h}$ (Fig. 4a). Additionally, a wound healing assay to assess HKC cell motility revealed increased an increased number of HKC/shTIR8 cells moving into the scratch wound in the presence of IL- $1 \beta$ over $12 \mathrm{~h}, 24 \mathrm{~h}$, and $48 \mathrm{~h}$ relative to 
Fig. 2 Ectopic expression of TIR8 negatively regulates IL- $1 \beta$-induced NF- $\mathrm{BB}$ activation in HKC cells. a, b Immunoblot analysis of TIR8 levels and NF- $\kappa \mathrm{B}$ activation (p-p65 levels) in HKC cells overexpressing $T I R 8$ in response to IL-1 $\beta . \mathbf{c}, \mathbf{d}$ Western blot analysis of TIR8 levels and NF- $\mathrm{\kappa B}$ activation in HKC/shTIR8 cells following exposure to IL- $1 \beta$ for $15 \mathrm{~m}$ a



$15 \mathrm{~m}$

$24 \mathrm{~h}$

\begin{tabular}{lll}
\multicolumn{3}{c}{ IL-1 $\beta$} \\
\hline HKC & VeC TIR8
\end{tabular}

\begin{tabular}{llllll}
\hline \multicolumn{3}{c}{$24 \mathrm{~h}$} \\
\hline HKC & Vec & TIR8 & & \multicolumn{3}{c}{ IL-1 } \\
& Vec & TIR8
\end{tabular}

$\longrightarrow-$
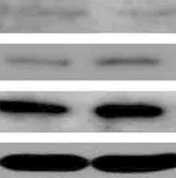

C



$\rightarrow$ TIR8/GAPDH $\nrightarrow$ p-p65/p65
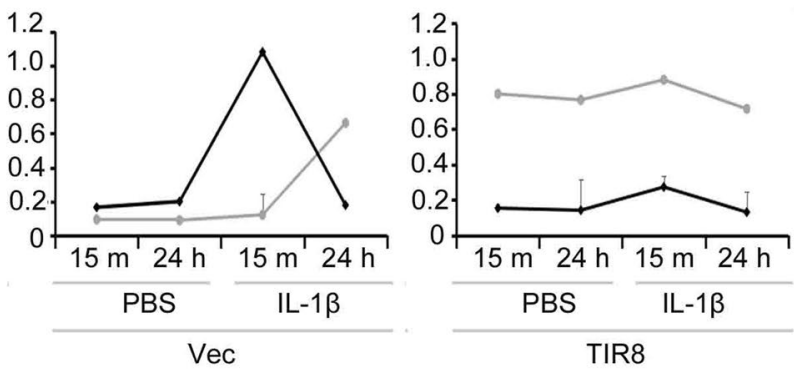

d

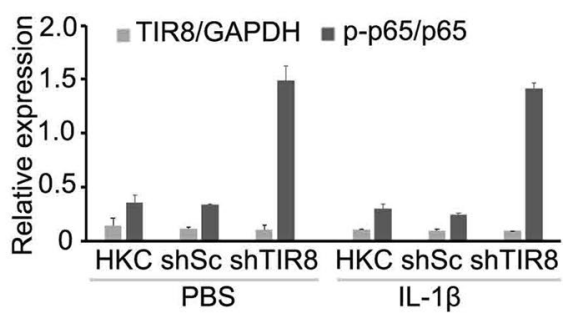

that observed by HKC/shSc cells (Fig. 4b). However, TIR8 overexpression inhibited cell migration and invasion in the absence of IL-1 $\beta$ (Fig. 4c and d).

\section{IL-1 $\beta$ activates NF-KB and promotes TGF- $\beta 1$-mediated EMT associated with TIR8 downregulation in an unilateral ureteric obstruction (UUO)-induced renal fibrosis model}

We established UUO-induced renal fibrosis animal models on SD rats to identify whether a negative feedback loop involving NF- $\mathrm{B} / \mathrm{TIR} 8$ regulates in vivo IL- $1 \beta$-induced EMT of tubular cells. Analysis of kidney function showed no dramatic alterations in 24-h urinary protein or serum urea between the sham-operated and UUO groups, whereas levels of serum urea and 24-h urinary creatinine, as well as 24-h urinary urea nitrogen, were significantly increased in the UUO group relative to the sham-operated group (Fig. 5a-e and Table 1). Additionally, kidneys in the UUO group were characterized by significant renal swelling, thinning of renal parenchyma, and hydronephrosis (Fig. 5f), whereas H\&E staining showed normal morphological structures in renal tissue sections from both the control and the sham-operated groups. Moreover, kidney damage in the forms of tubular dilatation, epithelial cell necrosis, hemorrhage, and inflammatory cell infiltration were observed in renal tissues from the UUO group (Fig. 5g), and collagen deposition was significantly increased in obstructed kidneys based on Masson trichrome staining. These findings confirmed establishment of the UUO-induced renal fibrosis model based on glomerular and tubular functions.

Immunohistochemistry analysis to detect levels of IL-1 $\beta$, TIR8, and activated-NF- $\mathrm{KB}$ (p-p65) revealed high levels of both IL-1 $\beta$ and p-p65 in renal tissues from the UUO group, whereas weak cytoplasmic IL-1 $\beta$ and nuclear p-p65 immunoreactivity was detected in renal tissues from both control and the sham-operated groups (Fig. 6). According to our in vitro findings, upregulated TGF- $\beta 1$ levels induced by IL-1 $\beta$ in kidneys following UUO might play central roles in initiation and progression of renal fibrosis. As expected, we observed elevated TGF- $\beta 1$ levels in tubular epithelial cells from UUO kidney tissue sections. Coincident with upregulated TGF- $\beta 1$, immunohistochemistry analysis showed decreases in E-cadherin levels, as well as increases 
a

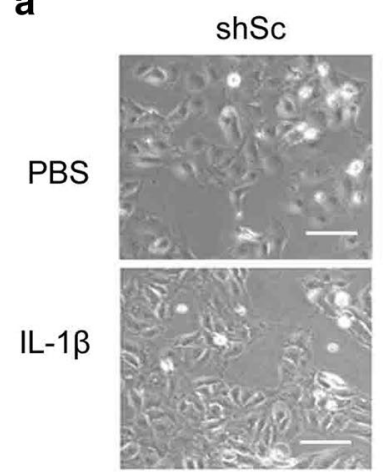
$\operatorname{shTIR8}$

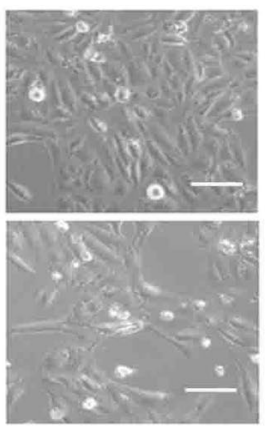

C

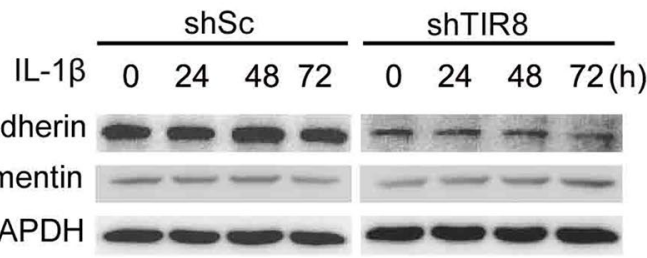

e



Fig. 3 Attenuated TIR8 expression facilitates IL-1 $\beta$-induced EMT in renal tubular epithelial cells. a Morphological alteration of $\mathrm{HKC} /$ shTIR8 cells treated with IL-1 $\beta(10 \mathrm{ng} / \mathrm{ml})$ for $72 \mathrm{~h}$ (scale bars: $20 \mu \mathrm{m})$. b qRT-PCR analysis of gene expression in HKC/shTIR8 cells treated with IL-1 $\beta(10 \mathrm{ng} / \mathrm{ml})$ for 24 and $48 \mathrm{~h} . * P<0.05$, $* * P<0.01$, $* * * P<0.001$. c Immunoblot analysis of E-cadherin and vimentin lev-

in vimentin levels. Importantly, we confirmed attenuated levels of TIR8 in renal tubular epithelial cells from the UUO group.

\section{Discussion}

IL-1 $\beta$ interacts with IL-1R and activates NF- $\kappa B$ to promote a wide range of biological effects capable of inducing morphological and phenotypic transdifferentiation of tubular epithelial cells into myofibroblast-like cells (Gasse et al. 2007; Stewart and Marsden 1995; Vesey et al. 2002). TIR8, a member of the IL-1R superfamily, is a potentially important regulator involved in this process. In the present study, we observed increased TIR 8 expression in HKC cells treated with IL-1 $\beta$ over a $24-\mathrm{h}$ period along with increases in p-p65 levels after $15 \mathrm{~m}$ of IL-1 $\beta$ induction, followed by a gradual


els in HKC/shTIR8 cells treated with IL-1 $\beta$ for $24 \mathrm{~h}, 48 \mathrm{~h}$, and $72 \mathrm{~h}$. d Immunofluorescence analysis of E-cadherin and vimentin levels in HKC/shTIR8 cells treated with IL- $1 \beta$ for $72 \mathrm{~h}$ (scale bars: $20 \mu \mathrm{m}$ ). e, f Immunoblot analysis of TGF- $\beta 1$ levels in HKC/shTIR8 cells treated with IL-1 $\beta$ for $24 \mathrm{~h}, 48 \mathrm{~h}$, and $72 \mathrm{~h}$. $* P<0.05$, $* * * P<0.001$

decrease from $30 \mathrm{~m}$ to $24 \mathrm{~h}$. TIR 8 knockdown to investigate TIR8-related physiological functions associated with IL-1/ IL-1R signaling revealed that IL- $1 \beta$ continually activated IL-1R/NF- $\kappa B$-related signaling in HKC/shTIR8 cells but not in normal HKC cells. To evaluate regulation of TIR8 expression by p-p65 (activated NF- $\mathrm{kB}$ ) following activation of IL-1R/NF- $\mathrm{kB}$ signaling, we knocked down p65 and found that activated NF- $\mathrm{\kappa B}$ promoted TIR 8 expression in $\mathrm{HKC}$ cells in the presence of IL-1 $\beta$.

Previous studies reported several molecules that negatively regulate IL-1R-mediated signaling to maintain a balance between inhibition and activation of the immune system (Divanovic et al. 2005; Thomassen et al. 1999). Some of these molecules are present constitutively to control IL-1R activation at the physiological level, whereas others are upregulated by IL-1R signaling in the presence of inflammatory stimuli to weaken the IL-1R response as part of a 
Fig. 4 Ectopic expression of TIR8 regulates motility and invasion of HKC cells. a Transwell assay evaluating the invasive ability of HKC cells overexpressing TIR8 (scale bars: $10 \mu \mathrm{m})$. $* * * P<0.001$. b Analysis of the migration of $\mathrm{HKC} /$ shTIR8 cells treated with IL- $1 \beta$ for $12 \mathrm{~h}, 24 \mathrm{~h}$, and $48 \mathrm{~h}$ (scale bars: $10 \mu \mathrm{m})$. $* P<0.05$, $* * P<0.01, * * * P<0.001$. c Analysis of the invasive ability of HKC/shTIR 8 cells treated with IL-1 $\beta$ for $48 \mathrm{~h}$ (scale bars: $10 \mu \mathrm{m}) . * P<0.05$. d Scratchwound assays evaluating the migration of HKC cells overexpressing TIR8 (scale bars: $10 \mu \mathrm{m}) . * * * P<0.001$

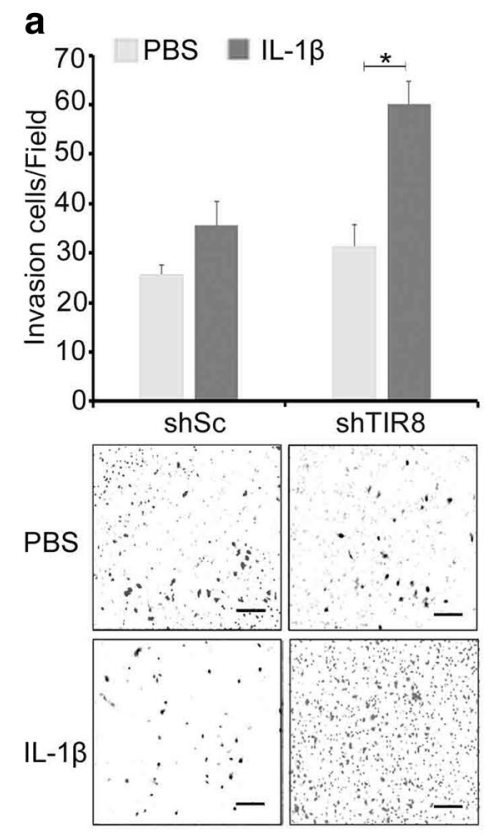

b


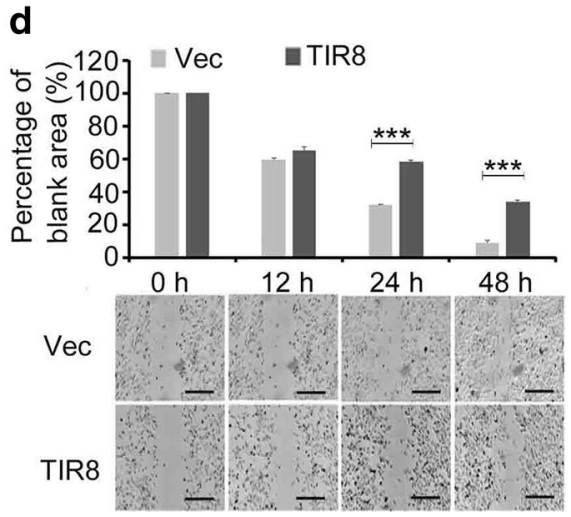

negative feedback loop (Li and Qin 2005; Qin et al. 2005). In this regard, IL-1R activation is a double-edged sword, with negative regulation of IL-1R signaling potentially required to avoid a continuous inflammatory response. This suggests a fine balance between regulation of short- and long-term inflammatory signaling in HKC cells, with this activity possibly involving TIR8. Our findings demonstrated that constitutive expression of TIR8 on the surface of HKC cells appeared to maintain a balance in immune-related signaling. Conversely, TIR 8 overexpression induced by activated $N F-\kappa B$ showed no significant effects on the activation of IL-1R/NF- $\kappa$ B signaling induced by IL- $1 \beta$ in HKC cells.

Previous studies indicate that glomerular and tubulointerstitial expression of IL-1 is elevated in glomerulonephritis (Niemir et al. 1997; Nikolic-Paterson et al. 1996). Additionally, Lemos et al. (2018) reported that IL-1 upregulation in human glomerulonephritis might result in EMT-induced interstitial fibrosis in vivo, because renal fibrosis is inhibited when blocking IL-1 activity using an
IL-1R antagonist (Chen et al. 1997). Recently, a positive correlation between $\mathrm{NF}-\kappa \mathrm{B}$ and activated EMT-related transcription factors, such as TWIST1 and Slug, was described in several human cancers (Liu et al. 2017; Pires et al. 2017). EMT is associated with the loss of epithelial traits and gain of mesenchymal characteristics, including altered cell migration and invasion. In the present study, evaluation of EMT following TIR8 knockdown in HKC cells and after IL-1 $\beta$ treatment revealed acquisition of a myofibroblast-like phenotype, significantly increased migration and invasion, loss of the epithelial marker E-cadherin, and gain of the mesenchymal marker vimentin. Additionally, IL-1 $\beta$ altered patterns of TWIST1 and Slug expression in HKC/shTIR 8 cells due to activation of NF- $\kappa \mathrm{B}$ as a transcriptional regulator of EMT-inducing factors related to metastatic progression (Fan et al. 2001). Moreover, as a canonical inducer promoting TWIST1 and Slug expression required for EMT, TGF- $\beta 1$ significantly increased autocrine signaling in $\mathrm{HKC} / \mathrm{shTIR} 8$ cells treated 
Fig. 5 Establishment of UUOinduced renal fibrosis animal models. a-e Analysis of kidney function in the sham-operated $(n=4)$ and UUO $(n=11)$ groups. $* P<0.05, * * P<0.01$ versus the sham-operated group. $\mathrm{Cr}$, creatinine, $\mathrm{UN}$, urea nitrogen. $\mathbf{f}$ Representative morphology of sham-operated (Sham) and UUO kidneys. G. $\mathrm{H} \& \mathrm{E}$ staining to evaluate renal histopathology and Masson trichrome staining to assess tubulointerstitial fibrosis (scale bars: $20 \mu \mathrm{m}$
Table 1 Analysis of kidney function in the sham-operated and UUO rats
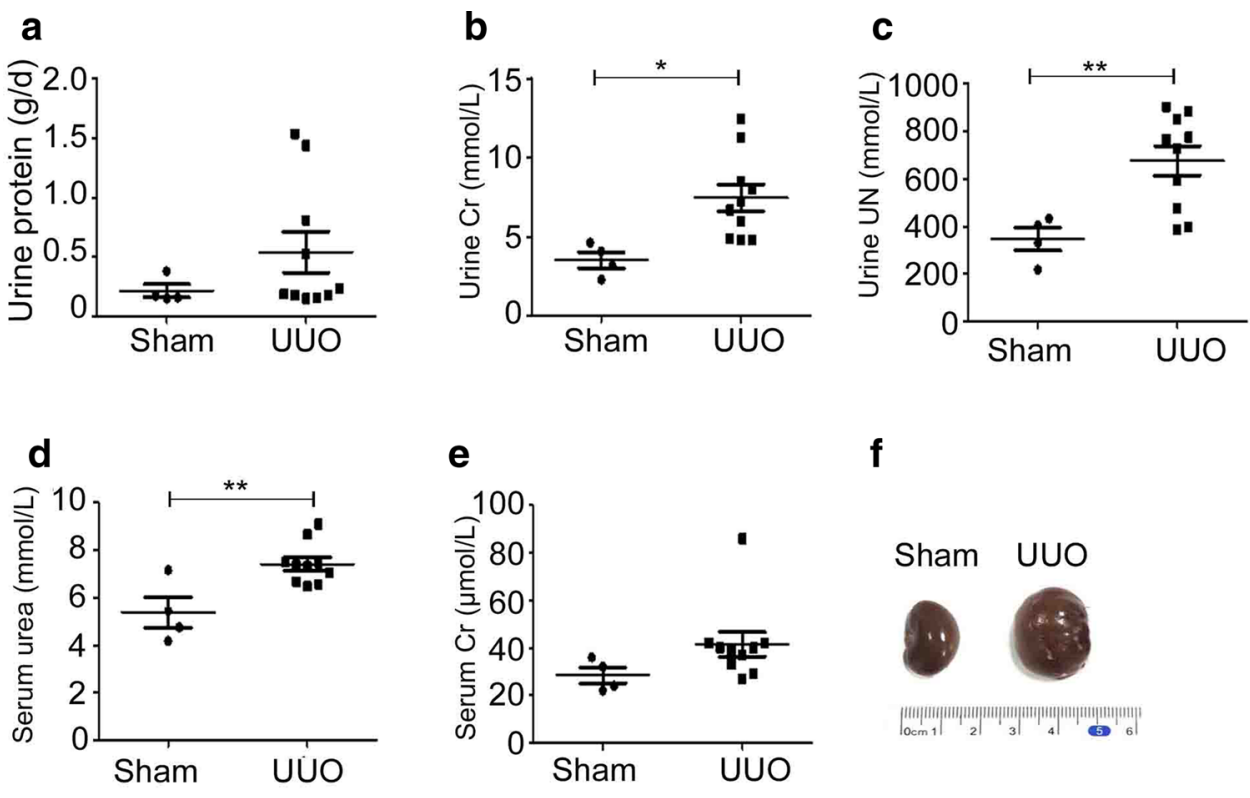

f

g
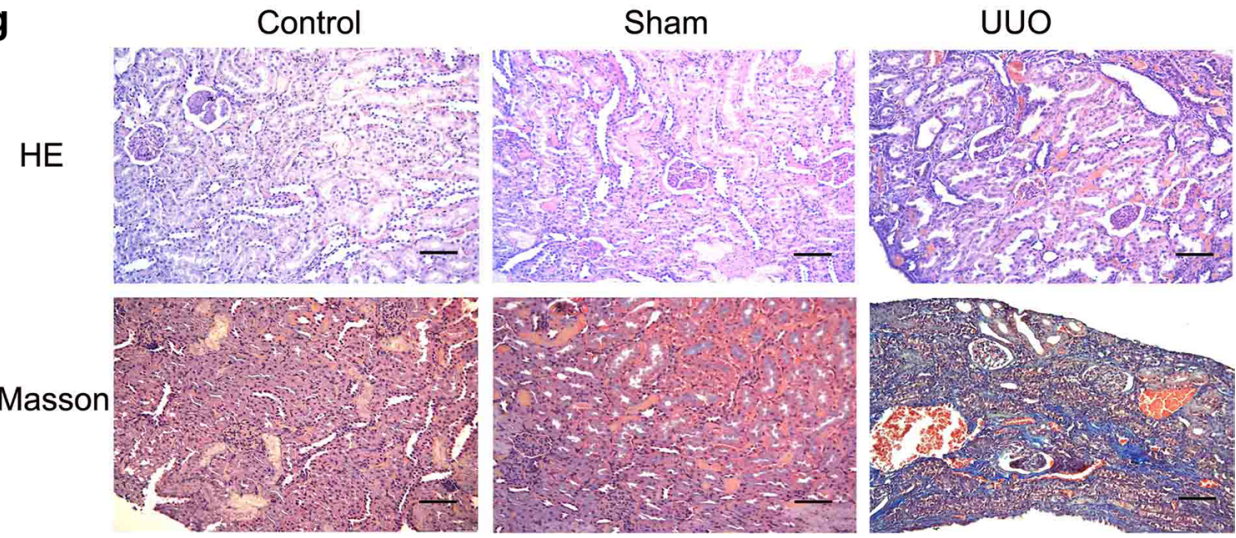

\begin{tabular}{llllll}
\hline Group & $\begin{array}{l}\text { Urine protein } \\
(\mathrm{g} / \mathrm{d})\end{array}$ & $\begin{array}{l}\text { Urine } \mathrm{Cr} \\
(\mathrm{mmol} / \mathrm{L})\end{array}$ & $\begin{array}{l}\text { Urine urea nitrogen } \\
(\mathrm{mmol} / \mathrm{L})\end{array}$ & $\begin{array}{l}\text { Serum urea } \\
(\mathrm{mmol} / \mathrm{L})\end{array}$ & $\begin{array}{l}\text { Serum } \mathrm{Cr} \\
(\mu \mathrm{mol} / \mathrm{L})\end{array}$ \\
\hline UUO $(n=4)$ & $0.54 \pm 0.54$ & $7.4 \pm 2.7$ & $677.01 \pm 198.54$ & $7.42 \pm 0.86$ & $41.50 \pm 16.5$ \\
Sham $(n=11)$ & $0.22 \pm 0.11$ & $3.5 \pm 1.0$ & $346.875 \pm 96.59$ & $5.39 \pm 1.30$ & $28.50 \pm 6.61$ \\
$P$ value & 0.099 & 0.016 & 0.009 & 0.005 & 0.057 \\
\hline
\end{tabular}

with IL-1 $\beta$. These results supported a protective role for TIR8 in IL-1 $\beta$-induced EMT in HKC cells.

In agreement with in vitro findings, in vivo experiments showed that IL- $1 \beta$-activated IL- $1 \mathrm{R} / \mathrm{NF}-\kappa \mathrm{B}$ signaling might contribute to upregulating TGF- $\beta 1$ levels and the development of kidney fibrosis. We observed attenuated TIR8 expression in renal tubular epithelial cells from animal models of UUO-induced renal fibrosis due to high levels of IL-1 $\beta$ and activated NF- $\kappa B$ (p-p65). This suggested that IL- $1 \beta$ might be capable of inducing EMT in renal tubular 
Fig. 6 IL- $1 \beta$ activates NF- $\kappa B$ signaling and promotes TGF$\beta 1$-mediated EMT in connection with TIR8 downregulation in UUO-induced renal fibrosis. Immunohistochemical analysis of IL- $1 \beta$, TIR8, p-p65, TGF- $\beta 1$, E-cadherin, and vimentin levels in renal tissues (scale bars: $20 \mu \mathrm{m})$. Control, normal kidney; Sham, sham-operated group; UUO, UUO-treated group

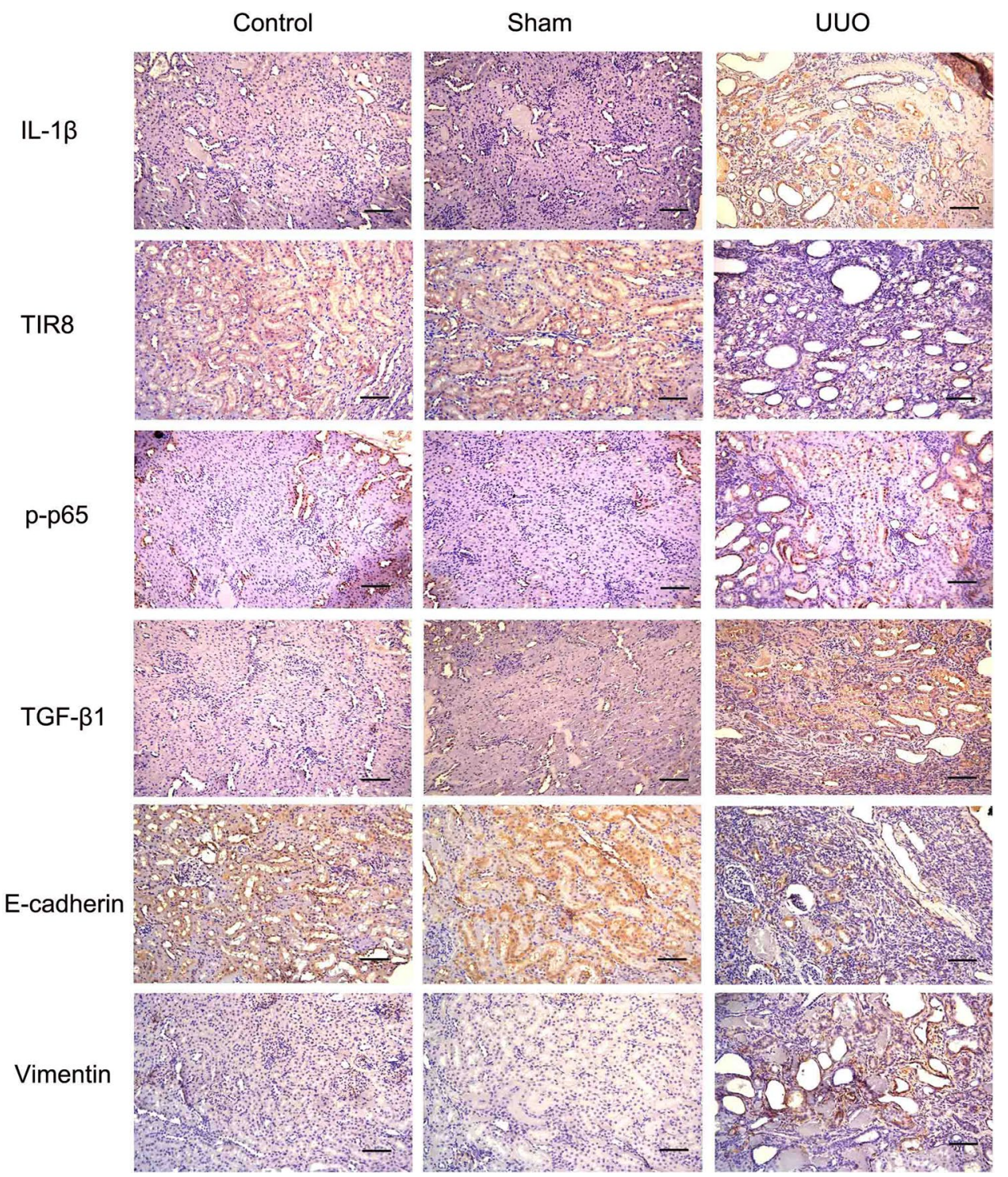

epithelial cells upon loss of TIR8-specific functions. Furthermore, renal tubular epithelial cells exposed to IL-1 $\beta$ acquired new migration and invasion abilities in vivo that might correlate with movement across the tubular basement membrane and ultimately into the interstitial compartments of the kidney.

In summary, we investigated TIR 8 expression in renal tubular epithelial cells following exposure to IL-1 $\beta$, as well as its regulatory mechanism associated with EMT in renal tubular epithelial cells. We found that TIR 8 was continuously expressed in renal tubular epithelial cells at the physiological levels and upregulated by activation of an NF- $\kappa \mathrm{B}$-mediated pathway during long-term IL- $1 \beta$ stimulus. Additionally, we observed that NF- $\kappa \mathrm{B}$ activation and subsequent upregulation of TGF- $\beta 1$ levels induced EMT in renal tubular epithelial cells. Furthermore, our findings suggested that TIR 8 overexpression might attenuate IL-1R/NF- $\mathrm{KB}$ signaling as part of a negative feedback loop (Fig. 7). These results provide new insights into TIR8-mediated negative regulation of IL-1R/NF-kB signaling, which is involved in EMT during RIF development. 


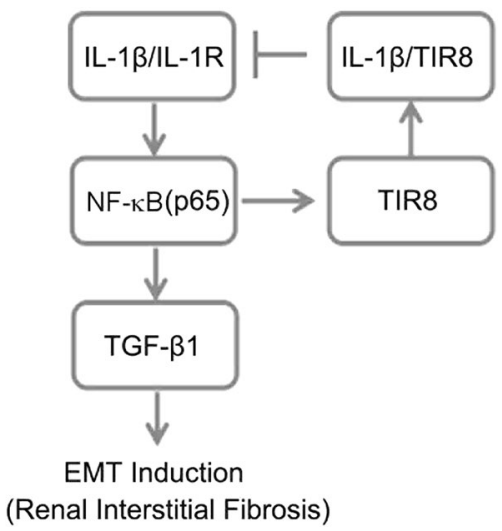

Fig. 7 Schematic illustration of TIR8-mediated regulation of IL-1 $\beta$ induced EMT via IL-1R/NF- $\mathrm{KB}$ signaling and negative feedback. Renal tubular epithelial cells maintain a balance between TIR 8 expression and activation of IL-1R signaling under physiological conditions. IL- $1 \beta$ activates NF- $\kappa B$ mediated by IL-1R signaling to increase TIR 8 expression. Overexpressed TIR 8 attenuates IL-1R signaling, and activated NF- $\mathrm{KB}$ promotes upregulated TGF- $\beta 1$ levels, which induces EMT in renal tubular epithelial cells

Supplementary Information The online version contains supplementary material available at https://doi.org/10.1007/s12079-021-00620-8.

Acknowledgements We thank Dr. Zhiqiang Zhang (The Second Affiliated Hospital of AHMU) for establishing experimental animal models.

Author contributions HSZ, DGW and KGJ designed the study; KGJ, YYZ, FH, MMZ, LZH, ZZT, TYL, DPX, MZ and LYG performed the experiments; KGJ, DGW and HSZ performed data analysis and interpretation; KGJ, YYZ, and DGW wrote the paper; HSZ edited the paper.

Funding This work was supported by the National Natural Science Foundation of China (Nos. 81772909 and 82071832).

\section{Declarations}

Conflict of interest The authors declare that they have no competing interests.

Open Access This article is licensed under a Creative Commons Attribution 4.0 International License, which permits use, sharing, adaptation, distribution and reproduction in any medium or format, as long as you give appropriate credit to the original author(s) and the source, provide a link to the Creative Commons licence, and indicate if changes were made. The images or other third party material in this article are included in the article's Creative Commons licence, unless indicated otherwise in a credit line to the material. If material is not included in the article's Creative Commons licence and your intended use is not permitted by statutory regulation or exceeds the permitted use, you will need to obtain permission directly from the copyright holder. To view a copy of this licence, visit http://creativecommons.org/licenses/by/4.0/.

\section{References}

Acloque H, Adams MS, Fishwick K, Bronner-Fraser M, Nieto MA (2009) Epithelial-mesenchymal transitions: the importance of changing cell state in development and disease. J Clin Invest 119(6):1438-1449

Chen A, Lai-Fa S, Wei-Yuan C, Shin-Chang T, Deh-Ming C, SanChi L, Fu-Gong L, Wei-Hwa L (1997) Interleukin-1 receptor antagonist modulates the progression of a spontaneously occurring IgA nephropathy in mice. Am J Kidney Dis 30(5):693-702

Dinarello CA, Wolff SM (1993) The role of interleukin-1 in disease. N Engl J Med 328(2):106-113

Divanovic S, Trompette A, Atabani SF, Madan R, Golenbock DT, Visintin A, Finberg RW, Tarakhovsky A, Vogel SN, Belkaid Y, Kurt-Jones EA, Karp CL (2005) Negative regulation of Toll-like receptor 4 signaling by the Toll-like receptor homolog RP105. Nat Immunol 6(6):571-578

Fan J-M, Huang X-R, Ng Y-Y, Nikolic-Paterson DJ, Mu W, Atkins RC, Lan HY (2001) Interleukin-1 induces tubular epithelialmyofibroblast transdifferentiation through a transforming growth factor- $\beta 1$-dependent mechanism in vitro. Am J Kidney Dis 37(4):820-831

Garlanda C, Riva F, Polentarutti N, Buracchi C, Sironi M, De Bortoli M, Muzio M, Bergottini R, Scanziani E, Vecchi A, Hirsch E, Mantovani A (2004) Intestinal inflammation in mice deficient in Tir8, an inhibitory member of the IL-1 receptor family. Proc Natl Acad Sci USA 101(10):3522-3526

Garlanda C, Riva F, Veliz T, Polentarutti N, Pasqualini F, Radaelli E, Sironi M, Nebuloni M, Zorini EO, Scanziani E, Mantovani A (2007) Increased susceptibility to colitis-associated cancer of mice lacking TIR8, an inhibitory member of the interleukin-1 receptor family. Cancer Res 67(13):6017-6021

Gasse P, Mary C, Guenon I, Noulin N, Charron S, Schnyder-Candrian S, Schnyder B, Akira S, Quesniaux VF, Lagente V, Ryffel B, Couillin I (2007) IL-1R1/MyD88 signaling and the inflammasome are essential in pulmonary inflammation and fibrosis in mice. J Clin Invest 117(12):3786-3799

Gupta SC, Sundaram C, Reuter S, Aggarwal BB (2010) Inhibiting NF-kappaB activation by small molecules as a therapeutic strategy. Biochim Biophys Acta 1799(10-12):775-787

Hao J, Liu S, Zhao S, Liu Q, Lv X, Chen H, Niu Y, Duan H (2011) $\mathrm{PI} 3 \mathrm{~K} / \mathrm{Akt}$ pathway mediates high glucose-induced lipogenesis and extracellular matrix accumulation in HKC cells through regulation of SREBP-1 and TGF-beta1. Histochem Cell Biol 135(2):173-181

Jinde K, Nikolic-Paterson DJ, Huang XR, Sakai H, Kurokawa K, Atkins RC, Lan HY (2001) Tubular phenotypic change in progressive tubulointerstitial fibrosis in human glomerulonephritis. Am J Kidney Dis 38(4):761-769

Lemos DR, McMurdo M, Karaca G, Wilflingseder J, Leaf IA, Gupta N, Miyoshi T, Susa K, Johnson BG, Soliman K, Wang G, Morizane R, Bonventre JV, Duffield JS (2018) Interleukin-1beta activates a MYC-dependent metabolic switch in kidney stromal cells necessary for progressive tubulointerstitial fibrosis. J Am Soc Nephrol 29(6):1690-1705

Li X, Qin J (2005) Modulation of Toll-interleukin 1 receptor mediated signaling. J Mol Med (Berl) 83(4):258-266

Liu H, Xiong J, He T, Xiao T, Li Y, Yu Y, Huang Y, Xu X, Huang Y, Zhang J, Zhang B, Zhao J (2017) High Uric Acid-Induced Epithelial-Mesenchymal Transition of Renal Tubular Epithelial Cells via the TLR4/NF-kB Signaling Pathway. Am J Nephrol 46(4):333-342

Meyer TW (2003) Tubular injury in glomerular disease. Kidney Int 63(2):774-787 
Nam NH (2006) Naturally occurring NF-kappaB inhibitors. MiniRev Med Chem 6(8):945-951

Niemir ZI, Stein H, Dworacki G, Mundel P, Koehl N, Koch B, Autschbach F, Andrassy K, Ritz E, Waldherr R, Otto HF (1997) Podocytes are the major source of IL-1 alpha and IL-1 beta in human glomerulonephritides. Kidney Int 52(2):393-403

Nikolic-Paterson DJ, Main IW, Tesch GH, Lan HY, Atkins RC (1996) Interleukin-1 in renal fibrosis. Kidney Int Suppl 54:S88-S90

Pires BR, Mencalha AL, Ferreira GM, de Souza WF, Morgado-Diaz JA, Maia AM, Correa S, Abdelhay ES (2017) NF-kappaB is Involved in the regulation of EMT genes in breast cancer cells. PLoS ONE 12(1):e0169622

Polentarutti N, Rol GP, Muzio M, Bosisio D, Camnasio M, Riva F, Zoja C, Benigni A, Tomasoni S, Vecchi A, Garlanda C, Mantovani A (2003) Unique pattern of expression and inhibition of IL-1 signaling by the IL-1 receptor family member TIR8/ SIGIRR. Eur Cytokine Netw 14(4):211-218

Qin J, Qian Y, Yao J, Grace C, Li X (2005) SIGIRR inhibits interleukin-1 receptor- and toll-like receptor 4-mediated signaling through different mechanisms. J Biol Chem 280(26):25233-25241

Riva F, Bonavita E, Barbati E, Muzio M, Mantovani A, Garlanda C (2012) TIR8/SIGIRR is an interleukin-1 receptor/toll like receptor family member with regulatory functions in inflammation and immunity. Front Immunol 3(3):322

Stewart RJ, Marsden PA (1995) Biologic control of the tumor necrosis factor and interleukin-1 signaling cascade. Am J Kidney Dis 25(6):954-966
Thomassen E, Renshaw BR, Sims JE (1999) Identification and characterization of SIGIRR, a molecule representing a novel subtype of the IL-1R superfamily. Cytokine 11(6):389-399

Torbohm I, Berger B, Schonermark M, von Kempis J, Rother K, Hansch GM (1989) Modulation of collagen synthesis in human glomerular epithelial cells by interleukin 1. Clin Exp Immunol 75(3):427-431

Vesey DA, Cheung CW, Cuttle L, Endre ZA, Gobe G, Johnson DW (2002) Interleukin-1beta induces human proximal tubule cell injury, alpha-smooth muscle actin expression and fibronectin production. Kidney Int 62(1):31-40

Zha X, Hu Z, Ji S, Jin F, Jiang K, Li C, Zhao P, Tu Z, Chen X, Di L, Zhou H, Zhang H (2015) NFkappaB up-regulation of glucose transporter 3 is essential for hyperactive mammalian target of rapamycin-induced aerobic glycolysis and tumor growth. Cancer Lett 359(1):97-106

Zhang Y, Ma X, Xie X, Sun G, Liang W, Li X, Wang F, Zhang L, Yan B, Fan J (2015) Role of P311 in interleukin-1alpha-induced epithelial to myofibroblast transition in kidney tubular epithelial cells. Ren Fail 37(8):1384-1389

Zheng C, Yin Q, Wu H (2011) Structural studies of NF-kappaB signaling. Cell Res 21(1):183-195

Publisher's note Springer Nature remains neutral with regard to jurisdictional claims in published maps and institutional affiliations. 